\title{
Formant characteristics of Malay vowels
}

\author{
Izzad Ramli ${ }^{1}$, Nursuriati Jamil' ${ }^{2}$, Norizah Ardi ${ }^{3}$ \\ ${ }^{1,2}$ Faculty of Computer and Mathematical Sciences, Universiti Teknologi MARA, Malaysia \\ ${ }^{3}$ Academy of Language Studies, Universiti Teknologi MARA, Malaysia
}

\begin{tabular}{l}
\hline \hline Article Info \\
\hline Article history: \\
Received Dec 3, 2019 \\
Revised Jan 28, 2020 \\
Accepted Feb19, 2020 \\
\hline
\end{tabular}

Keywords:

Acoustic phonetic

Formant analysis

International phonetic alphabet

Malay vowels

Vowel chart

\begin{abstract}
The purpose of this study was to investigate and examined the eight vowels formant characteristic of Malay language. Previous research of Malay language only investigated six basic vowels /a/, /e/, /i/, /o/, /u/, /o/. The vowels $/ \mathrm{o} /, / \varepsilon /$ that usually exist in a dialect were not included in the previous investigations. In this study, the vowels sound were collected from five men and four women producing the vowels /a/, /e/, /i/, /o/, /u/, /o/, $/ \mathrm{o} /, / \varepsilon /$ from different regions and dialects in Malaysia. Formant contours, F1 until F4 of the vowels were measured using interactive editing tool called Praat. Analysis of the formant data showed numerous differences between vowels in terms of average frequencies of $F 1$ and $F 2$, and the degree of overlap among adjacent vowels. When compared with the International Phonetic Alphabet (IPA), most pronunciation of the Malay vowels were at the same position but the vowel $/ \varepsilon /$ seen more likely to become a front vowel instead of a central vowel. Consequently, vowel features of the two Malay allophones $/ \mathrm{o} /$ and $/ \varepsilon /$ were documented and added to the IPA vowel chart. The findings form the fundamental basis for further research of speech synthesis, speech rehabilitation and speech reproduction of the Malay language.
\end{abstract}

This is an open access article under the CC BY-SA license.

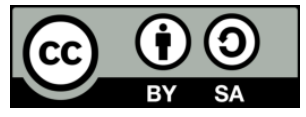

\section{Corresponding Author:}

Nursuriati Jamil,

Faculty of Computer and Mathematical Sciences,

Universiti Teknologi MARA,

40450 Shah Alam, Selangor, Malaysia.

Email: lizajamil@computer.org

\section{INTRODUCTION}

Phonology is described as an aspect of language dealing with rules for structuring and sequencing speech sound. In many languages such as American English, Chinese and Arabic, the acoustic characteristics of the vowels were well studied. This was not so for an under-resourced language such as Malay language [1]. Traditionally, the pronunciation of vowels in any language and Malay language was taught by referring to the International Phonetic Association (IPA) transcription sound chart. The documentation of the pronunciation of speech sounds was done by describing and distinguishing the vowel's sound produced through impressionistic [2-8]. Impressionistic means traditional research methods without using any instrument in identifying and reproducing the language. In this case, the phonetic members rely on hearing, vision, and sensitivity to their own speech organs to review each articulation [9]. Thus, there were possibilities of researches expressing varying opinions about the nature of vowels sounds of the Malay language. This situation was caused by hearing that vary among researchers.

The Malay language as described in the Encyclopedia Britannica [10] is a branch of the Austronesian language family, spoken by more than 33 million people of Malaysia, Indonesia, Southern Thailand, Singapore and Borneo [11]. The voice system of the Malay language varieties was shown to differ 
greatly encompassing virtually all variations of the Austronesian languages [12-14]. A study comparing five Malay/ Indonesian dialects were done to understand the voice systems of Austronesian family language. The dialects are prescriptive Standard Indonesian (SI), three Malay varieties spoken in the Malay heartland of Sumatra, Basd Selangon (BS), Sarang Lan Malay (SL), Mudung Darat Malay (MD) and the Malay of the city of Kuching in Sarawak (KM) [12]. Of all the Malay dialects, the most important dialect that has formed the basis of standard Malay language and the official language of Indonesia was the dialect of the southern Malay Peninsula [10]. Thus, the need to further document the phonological aspect of the Malay spoken language and dialects was imperative.

In the past decade, a number of studies on the Malay language vowels were conducted. Several investigations [15-18] were done on the phonetic properties of the six Malay vowels, /a/, /e/, /a/, /i/, /o/ and $/ \mathrm{u} /$. In $[19,20]$ employed image processing techniques on magnetic resonance imaging (MRI) to visualize the vocal tract in order to obtain dynamic articulatory parameters during production of the Malay vowels. In [15], four formant frequencies were used to analyze the sustained six vowels of Malay children aged between 7 and 12 years old. The aim was to investigate the acoustical differences of the speech production across age groups and gender. The results showed that the formant frequencies of the females were generally higher than the males. However, there was no significant difference in the formant frequencies of most vowels across the age groups. The authors [16] then analyzed the fundamental frequency $\left(\mathrm{F}_{0}\right)$ and perturbation measures of the vowels across age groups and gender. There was no significant $\mathrm{F}_{0}$ difference between the vowels for both males and females. However, a significant difference is shown across the age groups. The perturbation measures, on the hand, showed no significant difference across the age groups or gender. The extraction of vowel's fundamental frequency was also conducted on Malaysian Chinese young adults in [17]. As expected, the Malaysian Chinese females had significantly higher $\mathrm{F}_{0}$ than Malaysian Chinese males in all six vowels. There were also no significant differences in $\mathrm{F}_{0}$ across the vowels for each gender. In [18], Ting et al. extended the same research on Malaysian Malay young adults by extracting the $\mathrm{F}_{0}$ and perturbation measures from 6 sustained Malay vowels. They also concluded that there was no significant difference of $\mathrm{F}_{0}$ and perturbation measures in all vowels. The Malay females also have higher $\mathrm{F}_{0}$ compared to Malay males but no significant difference is found for perturbation measures across genders. However, comparisons on multiethnic showed that $\mathrm{F}_{0}$ varies between Malaysian Malay and other ethnic groups.

Most phonological studies on Malay vowels were to compare the acoustical differences of speech production between genders and across age groups. While these works were important and valuable towards adding knowledge in understanding spoken Malay language, the documentation of the speech pronunciations of standard Malay and its dialects using vowel charts will form the fundamental basis for further research such as speech synthesis, speech education, speech rehabilitation and speech reproduction. This is the motivation of our work. Furthermore, previous studies only explored on the sound productions of six standard Malay vowels /a/, /e/, /o/, /i/, /o/ and /u/. However, [21] compiled a list of nine Malay language vowels which consists of six standard vowel phonemes /a/, /e/, /i/, /o/, /u/, a/ and three allophones /o/, /ع/, /3/ that were frequently used in the dialect put forward by [5]. On the other hand, [21] and [22] later argued that

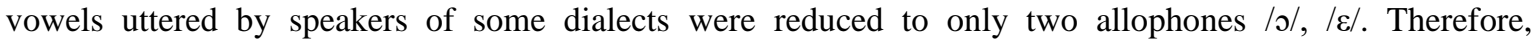
based on [21] and [22] arguments, we proposed to characterize the dynamic vowel pronunciations of eight Malay vowels $/ \mathrm{a} /, / \mathrm{e} /, / \mathrm{i} /, / \mathrm{o} /, / \mathrm{u} /, / \mathrm{\partial} /, / \mathrm{\jmath} /, / \varepsilon /$ using formant frequencies. The contributions of this paper are threefold: 1) The vowel features of two Malay allophones $/ \mathrm{o} /, / \varepsilon /$ were documented using technology instrument and illustrated in the IPA vowel chart and 2) The first and second formant frequencies of eight Malay vowels were quantified and documented, and 3) Audio collections of all eight Malay vowels were acquired from spoken Malay standard and dialects of four states in Malaysia.

\section{RESEARCH METHOD}

\subsection{Subjects}

The subjects were all native Malay speakers who use Malay language on daily basis. At the time of recording, all subjects have a complete articulatory tool with no history of speech disorder and were healthy. They were locals in their respective states and have been staying in the same district all their lives. For this paper, the subjects were consisting of four males and three females with age ranging from 40 to 60 years old.

\subsection{Equipments and procedures}

Unlike previous work that recorded the spoken vowels in a controlled enclosed environment, the recording of our subjects was done in open, outdoor environment. We selected our subjects and started a conversation with the subject at a place they were most comfortable such as their home, in a coffee shop and the market. The conversations were recorded from the spontaneous conversations using a Sony ICDTX650 16GB slim digital voice recorder which responses to $95-20000 \mathrm{~Hz}$ and battery life for recording up 
to 12 hours. The recorder was super slim, compact and lightweight for excellent recording quality and comfortable to be attached on the human body. The spoken words containing the vowels were selected from the conversations by a Malay language linguist and are shown in Table 1.

Table 1. The Malay vowels dataset

\begin{tabular}{cccc}
\hline Vowels & No of words & Duration of words & No of subjects \\
\hline a & 153 & 1 minute 30 seconds & 3 \\
e & 71 & 40 seconds & 3 \\
i & 124 & 1 minute 8 seconds & 3 \\
o & 99 & 56 seconds & 3 \\
u & 124 & 1 minute 6 seconds & 3 \\
o & 138 & 1 minute 28 seconds & 3 \\
o & 29 & 18 seconds & 2 \\
$\varepsilon$ & 12 & 7 seconds & 2 \\
\hline
\end{tabular}

In this research, seven subjects were used to record all the eight Malay vowels /a/, /e/, /i/, /o/, /u/, /ə/, $/ \mathrm{\rho} /, / \varepsilon /$. However, the vowels $/ \mathrm{\rho} /$ and $/ \varepsilon /$ were acquired from only six subjects that were able speak in dialects. One of the subjects can only speak in a standard Malay, thus only six vowels $/ \mathrm{a} /, \mathrm{e} /, / \mathrm{i} /, / \mathrm{o} /, / \mathrm{u} /$, and $/ \mathrm{a} /$ were acquired from this subject. Table 1 concludes that the vowels /a/, /i/, /u/ and /a/ are the most frequently used in spoken Malay language, followed by /o/, /e/, / / and $/ \varepsilon /$.

The collection of spoken words were pre-processed to remove the artefacts produced during recording. The spontaneous speech also suffered with filled pause and elongation that need to be determined and removed to preserve the quality of the spoken words [23-25]. The sampling frequency of the collected words is $16 \mathrm{kHz}$ in the mono channel with 16-bit bit resolution. Framing was done to the collected speech by blocking the speech signal into frames of $N$ samples. In our work, we used frame length of 20ms [26] with adjacent frames separated and shifted by $10 \mathrm{~ms}$ [27]. Windowing was applied after framing to minimize the signal discontinuities at the beginning and ending of each frame. It pre-multiplies the signal with Hanning window that smoothly decreased to zero value at each start and end frame. Hanning window was chosen because it produced a smoother and accurate signal [28] compared to Hamming or Blackman functions. The final step of pre-processing was filtering to suppress interfering signals and reduced environmental noise. High pass filtering is done using Audacity with different cut-off values depending on the background noise. The vowels were annotated manually from the spoken words using speech analysis tool known as Praat [29] by a technical person by referring to end point evaluation [30-31] as a guidence. Figure 1 illustrates the transcription of the speech words and vowels.

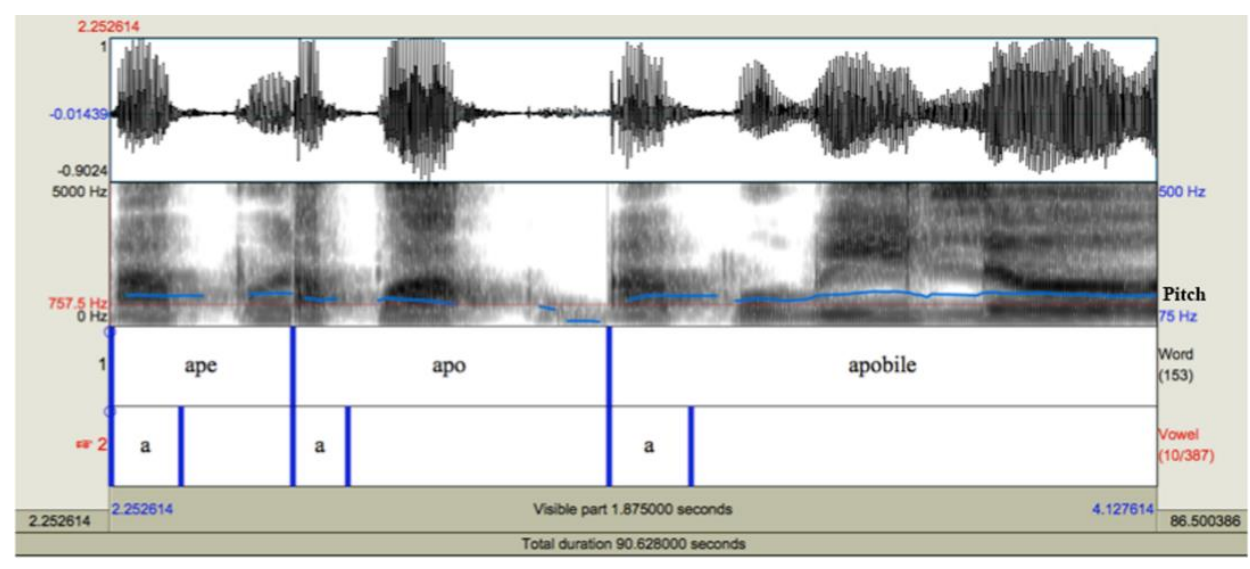

Figure 1. Transcription of the vowels /a/ from three Malay words, /ape/, /apo/, and /apobile/ done using Praat by a technical person. The selection of words and groupings of the vowels were done by a linguist

In Figure 1, the first row consists of the speech waveform. The second row illustrates the spectrogram of the speech waveform with the maximum frequency of $5000 \mathrm{~Hz}$. The blue coloured line is the pitch of the speech waveform. For annotation and labelling, the third and fourth rows represent the first and second tiers (marked as 1 and 2) for labelling level. The first and second tier show the manual labelling 
at word and vowel level, respectively. In this example, the vowel /a/ at the vowel level (second tier) was extracted and transcribed from three spoken words /ape/, /apo/, and /apobile/ at the word level (first tier). The beginning and ending of the vowel was determined based on three criteria: 1) a dramatic change in amplitude in the vowel's waveform, 2) a change in the energy of the vowel's formants accompanied by a change in complexity in the waveform indicating a loss of energy in F2 and F3, and 3) the onset of aperiodicity. A total of 750 vowels were extracted from the spoken words and were used to document the vowels pronunciations. As can be seen from Table 1, the highest number of vowel is for vowel /a/, followed by /ə/, /i/ and /o/. These are the most commonly used vowels in spoken Malay language.

\subsection{Vowel feature extraction}

Formant extraction was done using Praat [32] for all the vowels. The standard format settings of Praat was used that were $5500 \mathrm{~Hz}$ of maximum formant frequency, five numbers of formants, 25 milliseconds of window length, and a dynamic range of $30 \mathrm{~dB}$. An example of a spectrogram for vowel /a/ was illustrated in Figure 2.

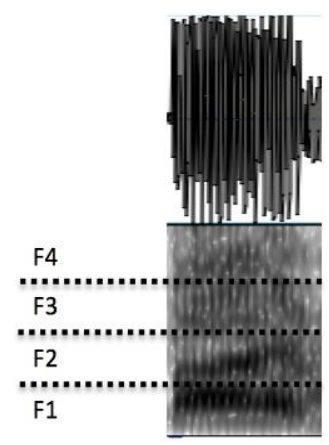

Figure 2. Gray-scale spectrogram and the formant frequencies of a vowel /a/ are demonstrated as an example. F1, F2, F3 and F4 are visualized

as the dark bands' spectrograms

The formant frequencies (F1-F4) for each vowel were calculated using the middle point value of formants for each sample. In Figure 2, the formants can be seen in a wideband spectrogram as dark bands. Meanwhile, Figure 3 illustrates the four formant frequencies of all 153 vowels of /a/. Overall, the distribution of each formant of vowel /a/ was shown to be discriminative. However, there was a few overlapping of formant frequencies particularly for F1 with F2, and F2 with F3 occurred due to the close resemblance of vowel speech productions. The F1 and F2 were important in determining the quality of vowels and were frequently said to correspond to the open or close of mouth position and front or back dimensions of the mouth [33]. On the contrary, high formant frequencies of F3 and F4 represent high pitch sounds especially in singing. F3 and F4 were manipulated by lowering the larynx and elevating the tongue blade to enhance this part of the spectrum and make it heard above an orchestral accompaniment [34].

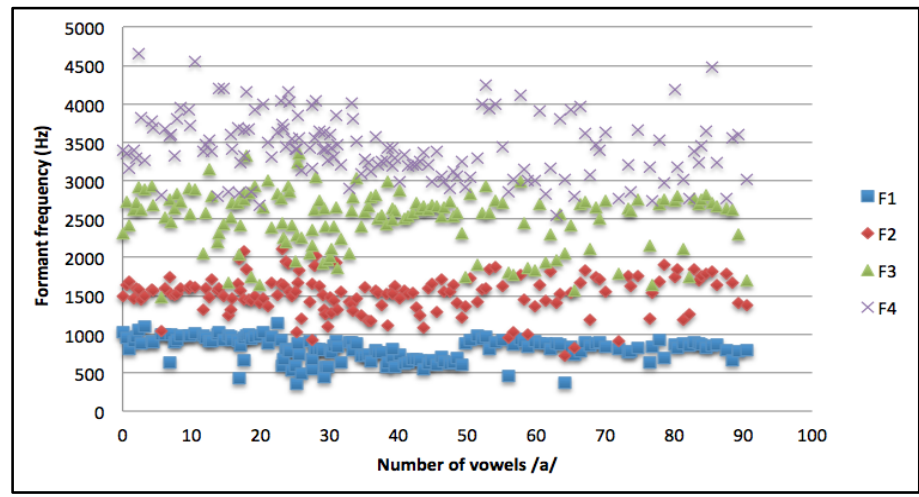

Figure 3. Formant frequencies (F1-F4) for all 153 vowels of /a/ collected from 3 subjects. Despite the visibly distinct colour-coded clusters of the formants, few overlapping formants of the vowel /a/ can be seen. 


\section{RESULTS AND DISCUSSION}

After the formant frequencies were extracted from all the eight vowels, the average formants (Hz) of each vowel were computed and tabulated in Table 2. As shown in the table, the average formants across all vowels are unique indicating the distinct pronunciations of each vowel.

Table 2. Average formant frequencies (F1-F4) for all eight vowels

\begin{tabular}{ccccc}
\hline & F1 & F2 & F3 & F4 \\
\hline /a/ & 811 & 1520 & 2496 & 3429 \\
/e/ & 499 & 1908 & 2559 & 3337 \\
/i/ & 432 & 2049 & 2763 & 3502 \\
/o/ & 547 & 1186 & 2373 & 3359 \\
/u/ & 477 & 1204 & 2462 & 3455 \\
/o/ & 556 & 1550 & 2459 & 3384 \\
/o/ & 665 & 1247 & 2657 & 3603 \\
/ $/ /$ & 690 & 1979 & 2647 & 3535 \\
\hline
\end{tabular}

Previous work [27] showed that the formant frequencies of the vowels differ in the frequencies of the first two formants. F1 and F2 were also commonly acknowledged as the main carriers of information necessary for vowel identification [25]. The discriminative characteristic of F1 and F2 were also used by [35] to classify gender of Malay children aged between 7 to 12 years old. Therefore, further analysis of F1 and F2 was deemed necessary in our work.

The frequencies of $\mathrm{F} 1$ and $\mathrm{F} 2$ for all eight vowels (/a/, /e/, /i/, /u/, /o/, /o/, /o/, , /) are illustrated in Figure 4. The high degree of crowding among adjacent vowels appears for the vowels (/a/, /e/, /u/, /o/, /o/, /o/, $\varepsilon /$ ). Meanwhile, the vowel $/ \mathrm{i} /$ is clustered separately at the top left of the crowded vowel area. Even though the vowels $(/ \mathrm{a} /, / \mathrm{e} /, / \mathrm{u} /, / \mathrm{\partial} /, / \mathrm{o} /, / \mathrm{\jmath} /, \varepsilon /)$ were clustered close to each other, the group of vowels were still identifiable. As an example, the cluster of vowels /a/ and / $\mathrm{u} /$ were highly populated at the bottom and top of the crowded area, respectively. The exact position of the Malay vowels can be determined based on the average formant frequencies F1 and F2 and is presented in the acoustic vowel diagram in Figure 5.

The value of the first and second formant frequencies represent the physical movement of the mouth during vowel's pronunciation. The first formant was to determine the height of the tongue body. If the vowel has a high first formant frequency, it indicated that the low tongue body was used to produce it. This type of vowel was called "low vowel". Based on Figure 5, the vowel /a/ has the high value of the first formant, therefore it was categorized as low vowel and low tongue body was used to pronounce it. For "high vowel", high tongue body was being used and this was shown by the low value of first formant frequency. For example, the vowel /i/ and /u/ have low first formant frequencies. Therefore, the vowels /i/ and / $\mathrm{u} /$ were categorized as high vowels. The other vowels $(/ \mathrm{e} /, / \mathrm{\jmath} /, / \mathrm{o} /, / \mathrm{\jmath} /, / \varepsilon /)$ were categorized as middle vowels between high and low vowel.

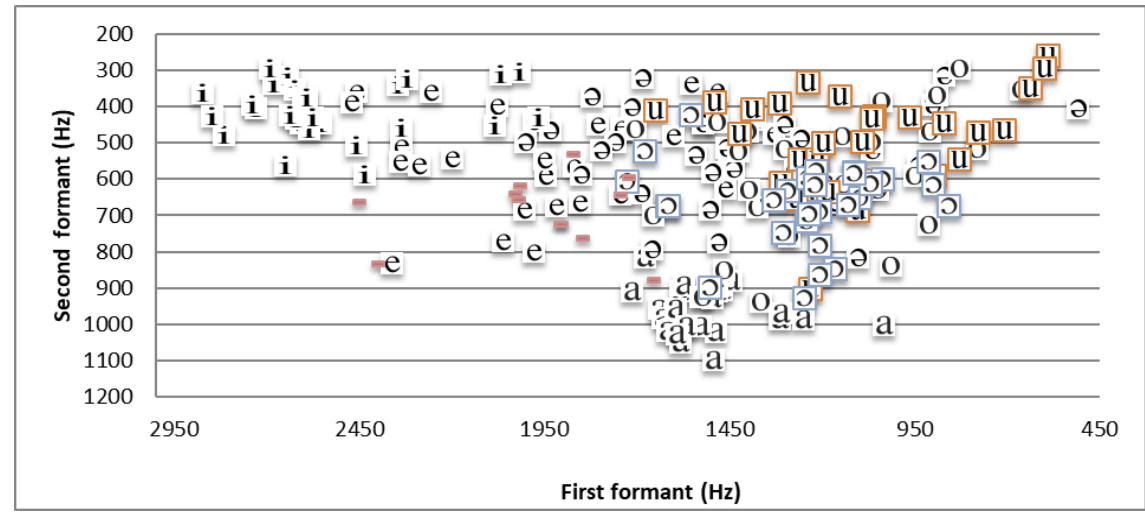

Figure 4. Tabulation of the 8 vowels for 4 males and 3 females. The data is thinned of redundant data points for better clarity of the display 


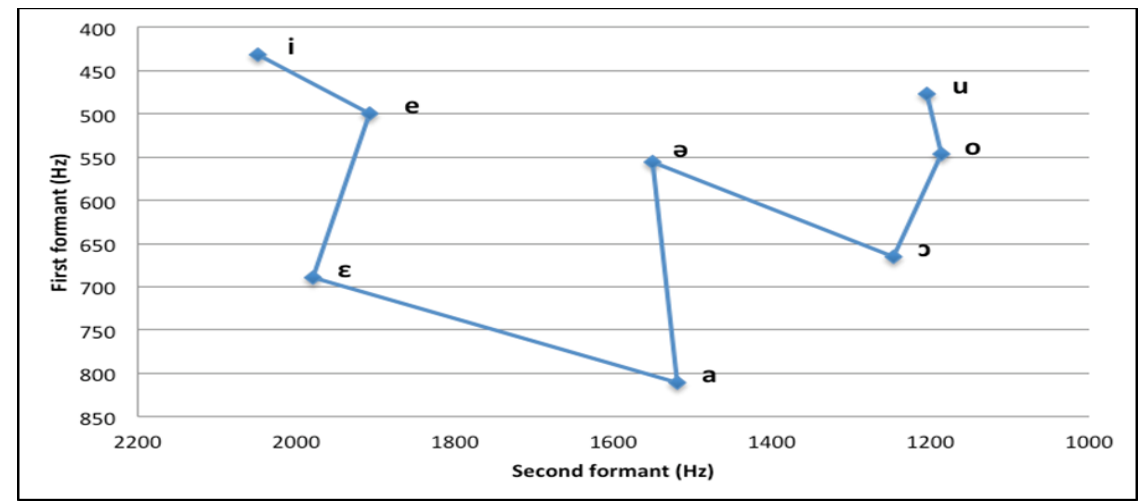

Figure 5. Vowel diagram of the Malay vowels spoken by 4 males and 4 females calculated using the average formant frequencies of F1 and F2.

The second formant value was mostly to determine the frontness or backness of the tongue body. If the vowels have high second formant frequency's value, it is pronounced at the front of the tongue body and categorized as "front vowel". Meanwhile, if it has low second formant frequency value, the sound is created at the back of the tongue body and is categorized as "back vowel". Based on Figure 5, the vowels (/i/, /e/, /ع/) have high second formant frequencies, therefore these vowels were categorized as front vowels which were produced at the front of the tongue body. The vowels $(/ \mathrm{u} /, / \mathrm{o} /, / \mathrm{o} /)$ with low second formant frequency were categorized as back vowels. Meanwhile, the vowels $(/ \mathrm{a} /, / \mathrm{o} /)$ located at the middle were categorized as central vowels.

We further analysed the vowel diagram based on gender as shown in Figure 6. In general, the females have a wider range of the first and the second formant. The lowest average first formant of the females was the vowel /i/ at $423 \mathrm{~Hz}$ and the highest average was for vowel /a/ at $841 \mathrm{~Hz}$. While for the males, the lowest average first formant was for vowel /i/ at $445 \mathrm{~Hz}$ and the highest average was for vowel /a/ at $685 \mathrm{~Hz}$. The difference between the first and second formant for the females was $418 \mathrm{~Hz}$, while for the males was $240 \mathrm{~Hz}$. This indicates that the degree of openness and closeness of the mouth during vowel pronunciation was larger for females compared to males. The same phenomenon was seen for the second formant frequencies. The females have a larger range of average second formant frequencies from $1180 \mathrm{~Hz}$ to $2200 \mathrm{~Hz}$, while the males ranged from $700 \mathrm{~Hz}$ to $1020 \mathrm{~Hz}$. The females showed the use of the front and back of the tongue more compared to males when pronouncing the vowels. It was also interesting to note that the vowel /i/ for male was pronounced more backness compared to vowel /e/, unlike in females where the vowel /i/ was more frontness than vowel /e/. The same occurrence was true for vowel /u/ and /o/ as can be seen in Figure 6. The vowel diagram of Figure 6 was mapped to the International Phonetic Alphabet (IPA) [36] to position the eight Malay vowels. The left side of the vowel diagram represented the portion of the mouth closer to the lips, and the right side represented the back of the mouth [37]. Vowel backness was a term referred to the position of the tongue during the articulation of a vowel relative to the back of the mouth. The top of the chart is the roof of the mouth and the bottom of the chart is the jaw. The completed vowels chart with the Malay vowels is shown in Figure 7.

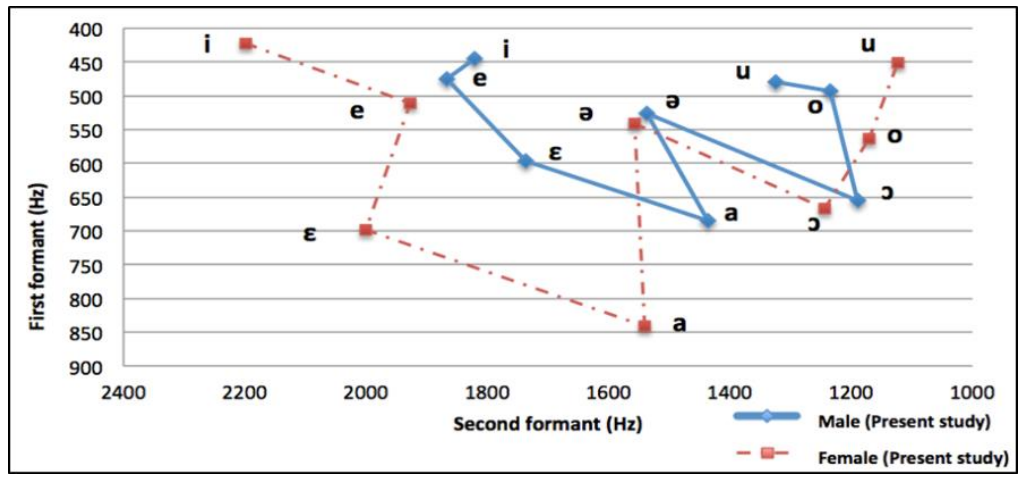

Figure 6. Vowel's diagram of the Malay vowels for males and females' categories 


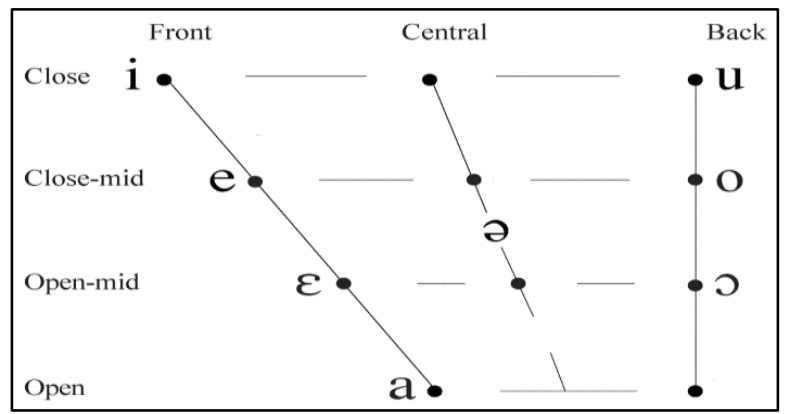

Figure 7. Vowels chart of the Malay vowels on the IPA

There were three main vowel features that can describe a vowel. The features were height, backness, and roundedness. The height and backness refer to the tongue position during vowel production. Roundedness refers to the lip's shape. The IPA calls high vowels differently as "close" vowels, and low vowels at the bottom as "open" vowels. The vowels in the middle rows were called "mid vowels". These terms described the state of the mouth during the vowel's pronunciation. Based on Figure 7 only vowel /a/ was identified as an open vowel and the two close vowels were /i/, and /u/. The other vowels were identified as close-mid or open-mid vowels. For the backness feature, the vowels on the right-hand side of the chart were called "back" vowels. Those on the left-hand side were called "front" vowels. Those in the middle were called "central" vowels. In Malay language there were three front vowels /i/, /e/, / $/$ / and three back vowels $/ \mathrm{u} /, / \mathrm{o} /, / \mathrm{o} /$. The others were the central vowels. Upon closer observation of the vowels position, vowel $/ \varepsilon /$ was located closer to the front compared to the same vowel in the IPA chart. Based on the observation, we can say that the vowel / $\varepsilon /$ when pronounced in Malay language was produced further up at the front of the mouth. Roundedness was the third major vowel feature and it described the lips and not the tongue. The front and central vowels were usually unrounded, and the back vowel is rounded. Therefore, the Malay language vowels /a/, /e/, /i/, / / /, / $/$ / were the unrounded vowels and vowels /o/, /u/, /o/ were the rounded vowels. We further quantified the eight vowels based on their average F1 and F2 and plot them over the vowel chart as $(\mathrm{F} 1, \mathrm{~F} 2)$. This is illustrated in Figure 8.

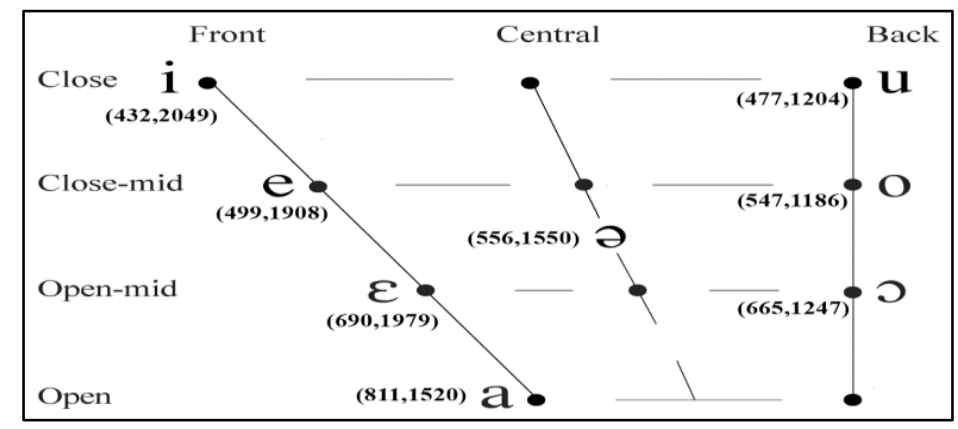

Figure 8. Vowels chart of the Malay vowels on the IPA with quantifications of first (F1) and second formant (F2) of each vowel. For example, vowel /i/ which is a high (close) vowel and pronounced at the front of the tongue has an average $(\mathrm{F} 1, \mathrm{~F} 2)$ of $(432,2049)$

Based on the overall average and standard deviation of the formant frequencies, we tabulated a general range of F1 and F2 for all the Malay vowels. The vowel height was represented using the first formant and its backness was represented using second formant. For example, if a vowel has an average first formant of $500 \mathrm{~Hz}$ and average of second formant of 1200, it was declared as a close-mid and back vowel. Any uncategorized vowel may be classified using this proposed generalized range. Generalization of vowel height and vowel backness based on the average of first and second formants. A vowel that falls in the range of 246 to to $663 \mathrm{~Hz}$ for its average first formants and having an average second formants in the range of 1065 to $2504 \mathrm{~Hz}$ was declared as high (close) and front vowels as shown in Table 3. 
Table 3. Generalization of vowel height and vowel backness based on the average of first and second formants

\begin{tabular}{llll}
\hline Vowel Height & F1 (Hz) & Vowel Backness & F2 (Hz) \\
\hline Close & $246-663$ & Front & $1065-2504$ \\
Close-mid & $370-676$ & Central & $1196-1904$ \\
Open-mid & $362-884$ & Back & $823-1610$ \\
Open & $658-964$ & & \\
\hline
\end{tabular}

\section{CONCLUSION}

This was the first initiative towards documenting all the eight vowels in Malay language using formant frequencies. In this paper, the Malay vowels of spontaneous speeches in Malaysia were investigated. The first and second formants frequencies of the eight vowels, (/a/, /e/, /i/, /u/, /ə/, /o/, /o/, / / /) were analyzed to objectively measure the openness and closeness of the mouth, and the frontness and backness of the pronunciation. The vowel diagram of the eight Malay vowels was charted to highlight the differences and similarities between vowels category and genders. This was the main contribution of this paper. Based on the vowel chart, it showed that the Malay dialect vowels comply with the IPA standard. The mean F1 and F2 for all eight vowels were documented for future references as research or as an educational tool for language learning. Compared to vowels produced by male and female, female have wider range of formant. However, further work needs to be done such as in-depth analysis of the formant frequencies in different dialect in Malaysia.

\section{REFERENCES}

[1] R. Arulmozhiyal and K. Baskaran, "Implementation of a fuzzy PI controller for speed control of induction motors using FPGA," Journal of Power Electronics, vol. 10, pp. 65-71, 2010.

[2] D. Zhang, et al., "Common mode circulating current control of interleaved three-phase two-level voltage-source converters with discontinuous space-vector modulation," 2009 IEEE Energy Conversion Congress and Exposition, vols. 1-6, pp. 3906-3912, 2009.

[3] Z. Yinhai, et al., "A novel SVPWM modulation scheme," in Applied Power Electronics Conference and Exposition, 2009. APEC 2009. Twenty-Fourth Annual IEEE, pp. 128-131, 2009.

[4] D. Hoesen, et al., "Shared-Hidden-Layer deep neural network for under-resourced language the content," Telkomnika, vol. 1, no. 3, pp. 1226-1238, June 2018.

[5] J.T. Collins, Anthology dialect of Malay Studies in Malay. Kuala Lumpur: Dewan Bahasa dan Pustaka, 1983.

[6] N.S. Karim, et al., Terengganu dialect. Kuala Lumpur: Dewan Bahasa dan Pustaka, 1989.

[7] A.H. Mahmood, "Terengganu dialects: A brief review in Malay," Jurnal Dewan Bahasa, pp. 217-225, 1990.

[8] M. Y. Maris, The Malay sound system. Kuala Lumpur: Fajar Bakti Sdn. Bhd, 1980.

[9] A. Omar, Hierarchy Malay language in Malay. Kuala Lumpur: Dewan Bahasa dan Pustaka, 1985.

[10] F.M. Onn, Aspects of Malay phonology and morphology: A generative approach. Universiti Kebangsaan Malaysia, 1980.

[11] I. Zahid and M. Shah Omar, Phonetics and phonology in Malay. Kuala Lumpur: PTS Professional, 2006.

[12] S. Mokhtar, et al., "Analysis of the principle frequency (F0) of Malay vowel sound: Transmission based on acoustic phonetics in Malay," Jurnal Bahasa, vol. 14, pp. 289-300, 2014.

[13] Encyclopedia Britannica. 2018. Retrieved September 3, 2018. [Online]. Available: https://www.britannica.com/ topic/Malay-language

[14] O.G.William and J. Archibald, Contemporary linguistica analysis: An introduction (7th edition). Toronto: Addison Wesley Longman, 2000.

[15] M. Donohue, "Malay as a mirror of austronesian: Voice development and voice variation," Lingua, vol. 118, no. 10, pp. 1470-1499, 2008.

[16] P. Cole and G. Hermon, "Voice in Malay/Indonesian," Lingua, vol. 118, no. 10, pp. 1500-1553, 2008.

[17] H. Thamrin, et al., "Crowdsourcing in developing repository of phrase definition in Bahasa Indonesia," TELKOMNIKA Indonesian Journal of Electrical Engineering, vol. 17, no. 5, pp. 2321-2326, 2019.

[18] H-N. Ting, et al., "Formant frequencies of Malay vowels produced by Malay children aged between 7 and 12 years," Journal of Voice, vol. 26, no. 5, pp. 664.e1-664.e6, 2012.

[19] H-N. Ting, et al., "Acoustic characteristics of vowels by normal Malaysian Malay young adults," Journal of Voice, vol. 25, no. 6, pp. e305-e309, 2011.

[20] A. Zourmand, et al., "A Magnetic resonance imaging study on the articulatory and acoustic speech parameters of Malay vowels," BioMedical Engineering Online, vol. 13, no. 1, pp. 1-20, 2014.

[21] H-N. Ting, et al., "Vocal fundamental frequency and perturbation measurements of vowels by Normal Malaysian Chinese adults," Journal of Voice, vol. 25, no. 6, pp. e311-e317, 2011.

[22] H-N. Ting, et al., "Fundamental frequency and perturbation measures of sustained vowels in Malaysian Malay children between 7 and 12 years old," Journal of Voice, vol. 26, no. 4, pp. 425-430, 2012. 
[23] R. Hamzah, N. Jamil, and N. Seman, "Filled pause classification using energy-boosted mel-frequency cepstrum coefficients," The 8th International Conference on Robotic, Vision, Signal Processing \& Power Applications (RoVISP 2013), pp. 311-319, 2013.

[24] R. Hamzah, N. Jamil, and N. Seman, "Acoustical analysis of filled pause in Malay spontaneous speech," Comput. Appl. Commun. Netw. Digit. Contents, vol. 350, pp. 251-259, 2012.

[25] R. Hamzah, "Discriminative classification model of filled pause and elongation for Malay language spontaneous speech," Universiti Teknologi Mara, 2016.

[26] A. Hassan, General linguistics: A series of teaching and learning of Malay language in Malay. Kuala Lumpur: PTS Professional, 2005.

[27] A. Othman, Initiating of Linguistic Science in Malay. Kuala Lumpur: Sarjana Enterprise, 1983.

[28] Ikkunointi. 2016. Windowing. [Online]. Available: http://www.cs.tut.fi/kurssit/SGN-4010/ikkunointi_en.pdf

[29] E.F. Shair, et al., "Determining best window size for an improved gabor transform in EMG signal analysis," TELKOMNIKA Indonesian Journal of Electrical Engineering, vol. 16, no. 4, pp.1650-1658, 2018.

[30] N. Seman et al., "Evaluating endpoint detection algorithms for isolated word from Malay parliamentary speech," International Conference on Information Retrieval \& Knowledge Management (CAMP), pp. 291-296, 2010.

[31] N. Seman, Z. Abu-Bakar, and N. Abu-bakar, "Measuring the performance of isolated spoken Malay speech recognition using Multi-layer Neural Networks," International Conference on Science and Social Research (CSSR 2010), pp. 182-186, 2010.

[32] P. Boersma, et al., Praat, Doing Phonetics by Computer, 2015. Retrieved May 20, 2001. [Online]. Available: http://www.praat.org/

[33] N. Amir, et al., "Quantifying vowel characteristics in Hebrew and Arabic," Afeka-AVIOS Speech Processing Conference, pp. 37-43, 2012.

[34] B.H. Story, The vocal tract in singing (Vol. 1). Tucson: Oxford University Press, 2016.

[35] D.K. Phull and G.B. Kumar, "Vowel analysis for Indian English," Procedia Computer Science, vol 93, pp. 33-538, September 2016.

[36] W. Ruter, 2018. Full IPA Chart. [Online]. Availlable: https://www.internationalphoneticassociation.org/ content/full-ipa-chart

[37] J. Hillenbrand and L.A. Getty, "Acoustic characteristics of American English vowels," The Journal of the Acoustical Society of America, vol. 49008, no. 1994, pp. 3099-3111, 1995.

Int. J. Eval. \& Res. Educ. Vol. 9, No. 1, March 2020: 144 - 152 